\title{
Microtensile Bond Strength of Bulk-fill Resin Composite Restorations in High C-factor Cavities
}

\author{
Isabelle Lins Macêdo de Oliveira ${ }^{1}$, Oscar Felipe Fonseca de Brito², Laís Maciel Costa Gabriela Queiroz de Melo Monteiro ${ }^{3}$, \\ Marcos Antônio Japiassu Resende Montes ${ }^{4}$
}

\begin{abstract}
Aim: To evaluate the microtensile bond strength ( $\mu$ TBS) and the fracture modes of four bulk-fill resin composites (Tetric EvoCeram Bulk Fill/ Ivoclar Vivadent, Filtek Bulk Fill/3M ESPE, Venus Bulk Fill/Heraus Kulzer, and Filtek Bulk Fill Flow/3M ESPE) and one conventional incrementally filled resin composite (Filtek Z250/3M ESPE) inserted in class I cavities, after 24 hours and 6 months of water storage.

Materials and methods: In all, 30 sound human extracted molars were divided into five restorative groups. Standardized class I cavities were prepared and restored following the manufacturer's instructions. The restored teeth were then assigned into one of the storage times ( $24 \mathrm{hours}$ or 6 months). The molars were then cut into $1 \mathrm{~mm}^{2}$ sticks and submitted to $\mu$ TBS. All fractured specimens were analyzed under a stereomicroscope (40X). Data were submitted to analysis of variance (ANOVA) and the Tukey post hoc test was applied for comparison between groups; and paired $t$ test for comparison within storage times $(p=0.05)$.

Results: After 24 hours of storage, statistically significant differences were observed between Filtek Z250 and Filtek Bulk Fill Flow groups. However, after 6 months, no statistical differences were observed between groups. Additionally, no differences were observed for the $\mu$ TBS between the storage times. Adhesive failures were the most frequent fracture mode after 24 hours (54\%) and 6 months (43\%), the resin cohesive fracture mode showed $16 \%$ for 24 hours and 14\% for 6 months, the dentin cohesive fracture mode showed 14\% for 24 hours and $26 \%$ for 6 months, and the mixed fracture mode showed $16 \%$ for 24 hours and $17 \%$ for 6 months.

Conclusion: Bulk-fill resin composites obtained similar $\mu$ TBS in high C-factor cavities as conventional incrementally filled resin composites. No bond strength reduction was observed after 6 months of storage.

Clinical significance: Single increment restorations in high C-factor cavities with bulk-fill resin composites did not reduce $\mu$ TBS after 24 hours or 6 months of storage. The comparable results to the conventional incrementally filled resin composites and the reduction in the operative time, make the bulk-fill resin composites a restorative option for posterior teeth restorations.

Keywords: Composite resins, Dental bonding, Dentin, Laboratory research, Tensile strength.

The Journal of Contemporary Dental Practice (2020): 10.5005/jp-journals-10024-2846
\end{abstract}

\section{INTRODUCTION}

When cavities with high C-factor are filled with large amounts of restorative material, the integrity of the bond interfaces is at risk and, therefore, the longevity of the restorative procedure. The incremental filling techniques are capable of reducing stress concentration at the tooth/restoration interface due to a reduction in resin volume during filling, and this has been associated with higher bond strength values when compared with those obtained when using the bulk-filling technique. Stresses developed at the tooth/restoration interface can cause cusp deflection, microcracks, development of cracks, microleakage, postoperative sensitivity, and secondary caries., ${ }^{1,2}$

The modulus of elasticity has been accepted as being more critical than the polymerization shrinkage in determining the stresses. In this sense, the modulus of elasticity of restorative materials influences their behavior concerning the stresses generated. In vitro studies have shown that the stresses generated at the bond interface during composite shrinkage are positively correlated with the stiffness of the material. Thus, the higher the modulus of elasticity and the polymerization shrinkage of the composite, the higher will be the stresses at the interface. ${ }^{3,4}$

The incremental stratification up to $2 \mathrm{~mm}$ thick has been accepted as a standard technique for filling resin composites into cavities, followed by curing. A distinct advantage of this technique is to limit the thickness of resin to be penetrated by light, so that

\begin{abstract}
${ }^{1-4}$ Dental School, Universidade de Pernambuco, Camaragibe, Pernambuco, Brazil

Corresponding Author: Isabelle Lins Macêdo de Oliveira, Dental School, Universidade de Pernambuco, Camaragibe, Pernambuco, Brazil, Phone: +55 8131847659, e-mail: isabelle_lins_@hotmail.com

How to cite this article: de Oliveira ILM, Fonseca de Brito OF, de Melo Monteiro LMCGQ, et al. Microtensile Bond Strength of Bulk-fill Resin Composite Restorations in High C-factor Cavities. J Contemp Dent Pract 2020;21(6):626-631.

Source of support: Nil

Conflict of interest: Coordenacão de Aperfeiçoamento de Pessoal de Nível Superior, Brasil (CAPES) - Finance Code 001
\end{abstract}

the luminous energy transmitted decreases exponentially with increasing thickness. Therefore, by limiting this increment thickness, adequate penetration of light and more effective polymerization are provided, resulting in improved physical properties, better marginal adaptation, and decreased cytotoxicity. Despite these benefits, the incremental technique has the disadvantages such as the possibility of incorporating voids or contamination between the layers of resin composite, the occurrence of adhesive failures between increments, the difficulty of filling due to limited access in conservative preparations, and increase in the time required for filling and polymerizing each layer. ${ }^{5,6}$ 
To reduce clinical time in restorative procedures, manufacturers introduced bulk-fill resin composites in the market. These materials are mostly indicated for posterior teeth restorations that can be inserted in single increment of 4-5 mm thick with one-step curing. ${ }^{4,5,7-16}$ The use of increased increment thicknesses of bulkfill composites is due to the evolution of the dynamics of their photoinitiation system and their high translucency, allowing the penetration of additional light and a greater depth of cure. ${ }^{17,18}$

The main interest in the commercialization of this material is the saving of clinical time and, therefore, the cost. However, other aspects are also clinically relevant, such as lower rates of polymerization shrinkage stress, greater depth of cure, minor crack formation, and marginal adaptation. ${ }^{19}$ Thus, the purpose of this study was to evaluate the $\mu$ TBS of bulk-fill resin composite restorations in cavities with high C-factor using the microtensile bond test and the fracture mode of the specimens after 24 hours and 6 months of storage. The hypotheses investigated demonstrated that the $\mu$ TBS of bulk-fill resin composites would be similar to the conventional resin composite with incremental filling and that the $\mu$ TBS values would be higher with the storage time of 24 hours.

\section{Materials and Methods}

\section{Experimental Design}

This in vitro study was approved by the local ethics committee of Universidade de Pernambuco under protocol number 971.605. The study was conducted at the Center for Research in Biomaterials of the Dental School, Universidade de Pernambuco.

Extracted noncavitated human molars were donated from patients who attended the dental surgery clinic after signing informed consent. The teeth were stored in $0.5 \%$ chloramine T solution, at room temperature, for 7 days for disinfection, as recommended by the International Organization for Standardization (ISO) technical specification No. $11405 .^{20}$ Thirty teeth were selected and randomly divided into five groups, according to the restorative materials tested (Tetric EvoCeram Bulk Fill/TBF, Filtek Bulk Fill/FBF,

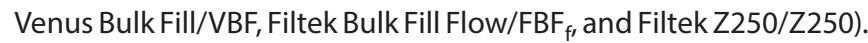
All groups were further subdivided into two subgroups, according to the storage time ( 24 hours and 6 months).

\section{Cavity Preparation}

The occlusal enamel was ground flat using a polisher (Politriz ERIOS-27,000, São Paulo, São Paulo, Brazil), with wet 600-grit silicon carbide abrasive paper (Carborundum Abrasivos Ltda., São Paulo, São Paulo, Brazil) under running water. Standardized class I cavities (4 mm long, $4 \mathrm{~mm}$ wide, $4 \mathrm{~mm}$ deep) were prepared using a diamond cylindrical bur (No. 3146; KG Sorensen, Cotia, São Paulo, Brazil) in a high-speed handpiece with copious air-water spray and finished with a superfine bur.

\section{Restorative Procedures}

The materials used in this study, and the composition and restorative techniques are listed in Table 1. Selective enamel etching was performed in all teeth with $37 \%$ phosphoric acid (Condac 37; FGM, Joinville, Santa Catarina, Brazil) for 30 seconds and thoroughly washed in water. All the cavities were restored with a two-step self-etching primer/adhesive system, Clearfil SE Bond (Kuraray MedicalCorp., Tokyo, Japan). Bonding procedures were performed according to the manufacturer's instructions (the cavities were treated with Clearfil SE Bond primer for 20 seconds
Table 1: Composition and characteristics of the materials used in the study

\begin{tabular}{|c|c|c|c|c|}
\hline $\begin{array}{l}\text { Mate- } \\
\text { rial (batch } \\
\text { number) }\end{array}$ & $\begin{array}{l}\text { Filler } \\
\text { loading } \\
\text { (wt\%/vol\%) }\end{array}$ & Matrix & $\begin{array}{l}\text { Restorative } \\
\text { technique }\end{array}$ & Manufacturer \\
\hline $\begin{array}{l}\text { Tetric } \\
\text { EvoCeram } \\
\text { Bulk } \\
\text { Fill-TBF } \\
\text { (T23727) }\end{array}$ & $80 / 60$ & $\begin{array}{l}\text { Bis-GMA, } \\
\text { BisEMA, } \\
\text { UDMA }\end{array}$ & $\begin{array}{l}\text { Single } \\
\text { increment- } \\
\text { Medium } \\
\text { viscosity } \\
\text { (bulk-filling) }\end{array}$ & $\begin{array}{l}\text { Ivoclar } \\
\text { Vivadent, } \\
\text { Schaan, } \\
\text { Liechtenstein }\end{array}$ \\
\hline $\begin{array}{l}\text { Filtek Bulk } \\
\text { Fill-FBF } \\
\text { (N604392) }\end{array}$ & $76.5 / 58.4$ & $\begin{array}{l}\text { Bis-GMA, } \\
\text { BisEMA, } \\
\text { UDMA }\end{array}$ & $\begin{array}{l}\text { Single } \\
\text { increment- } \\
\text { Medium } \\
\text { viscosity } \\
\text { (bulk-filling) }\end{array}$ & $\begin{array}{l}\text { 3M ESPE, St. } \\
\text { Paul, MN, } \\
\text { USA }\end{array}$ \\
\hline $\begin{array}{l}\text { Venus Bulk } \\
\text { Fill-VBF } \\
(010105)\end{array}$ & $65 / 38$ & $\begin{array}{l}\text { UDMA, } \\
\text { EBADMA }\end{array}$ & $\begin{array}{l}\text { Single } \\
\text { increment- } \\
\text { Flow (bulk- } \\
\text { filling) }\end{array}$ & $\begin{array}{l}\text { Heraeus } \\
\text { Kulzer, } \\
\text { GmbH, } \\
\text { Hanau, } \\
\text { Germany }\end{array}$ \\
\hline $\begin{array}{l}\text { Filtek } \\
\text { Bulk Fill } \\
\text { FlowFBFf } \\
\text { (N653221) }\end{array}$ & $64.5 / 42.4$ & $\begin{array}{l}\text { Bis-GMA, } \\
\text { BisEMA, } \\
\text { UDMA, } \\
\text { Procrylat }\end{array}$ & $\begin{array}{l}\text { Single } \\
\text { increment- } \\
\text { Flow (bulk- } \\
\text { filling) }\end{array}$ & $\begin{array}{l}\text { 3M ESPE, St. } \\
\text { Paul, MN, } \\
\text { USA }\end{array}$ \\
\hline $\begin{array}{l}\text { Filtek } \\
\text { Z250-Z250 } \\
(312565)\end{array}$ & $82 / 60$ & $\begin{array}{l}\text { Bis-GMA, } \\
\text { BisEMA, } \\
\text { UDMA }\end{array}$ & $\begin{array}{l}\text { incremental } \\
\text { filling- } \\
\text { Medium } \\
\text { viscosity }\end{array}$ & $\begin{array}{l}\text { 3M ESPE, St. } \\
\text { Paul, MN, } \\
\text { USA }\end{array}$ \\
\hline \multirow[t]{2}{*}{$\begin{array}{l}\text { Clearfil SE } \\
\text { Bond-CSEB }\end{array}$} & \multicolumn{2}{|c|}{$\begin{array}{l}\text { Primer: MDP, HEMA, } \\
\text { dimethacrylate, } \\
\text { water, photoinitiator, } \\
\text { N-diethanol-p-toluidine. } \\
\text { Lot: } 01249 \mathrm{~A}\end{array}$} & $\begin{array}{l}\text { Bonding } \\
\text { agent }\end{array}$ & $\begin{array}{l}\text { Kuraray } \\
\text { Medical Inc., } \\
\text { Tokyo, Japan }\end{array}$ \\
\hline & \multicolumn{2}{|c|}{$\begin{array}{l}\text { Bond: Bis-GMA MDP, } \\
\text { HEMA, hydrophobic } \\
\text { dimethacrylate, } \\
\text { photoinitiator. Lot: } \\
\text { 01887A }\end{array}$} & & \\
\hline
\end{tabular}

and dried for 10 seconds, then Clearfil SE Bond bonding agent was applied, air thinned, and light-cured for 10 seconds). All light-curing procedures were performed with an LED unit (Radii-cal $1200 \mathrm{~mW} /$ $\mathrm{cm}^{2}$; SDI, Bayswater, Australia).

The cavities were filled with resin composite using either bulk or incremental technique. For the incremental group, the cavities were filled in three similar oblique increments. Each layer was light irradiated for the time indicated in the manufacturer's instructions. For the bulk-fill groups, the cavities were filled with resin composite in one increment and exposed to light irradiation for the time indicated in the manufacturer's instructions.

After the restorative procedure, teeth were X-rayed to check the depth of the restoration and the proportion of resin/dentin. Equal proportions of both substrates should be observed in the "sticks" to be tested.

\section{Microtensile Bond Strength Measurement}

Immediately after the restorative procedure, the specimens were serially sectioned using a low-speed diamond saw (Isomet Diamond Wafering Blades; Buehler, Lake Bluff, IL, USA) under water cooling. Cutting was done across the bonded interface to obtain sticks with a cross-sectional area of around $1 \mathrm{~mm}^{2}$ measured with a digital 
caliper (Digimess, São Paulo, São Paulo, Brazil). An average of eight adequate sticks was obtained from each tooth, with the top half consisting of resin composite and the bottom half consisting of dentin. For each resin composite, a total of 20 sticks were assigned for the 24-hour storage and another 20 sticks for 6-month storage in distilled water at $37^{\circ} \mathrm{C}$. The sticks were individually fixed to a testing device with cyanoacrylate glue (Super Bond Gel Control-Loctite; Henkel Ltda., São Paulo, São Paulo, Brazil) and were subjected to microtensile testing in a machine (KRATOS IKCL3-USB; Taboão da Serra, São Paulo, Brazil) at $0.5 \mathrm{~mm} /$ minute until failure. The $\mu$ TBS was calculated by dividing the fracture load by the surface area.

\section{Fracture Mode Analysis}

For fracture mode analysis after the microtensile bond test, the specimens were evaluated under a stereomicroscope at $40 \times$ magnification (Leica DM 4000M; Bensheim, Hessen, Germany). The fracture mode was classified as a cohesive failure in dentin, a cohesive failure in resin composite, adhesive failure, and mixed failure.

\section{Scanning Electron Microscopy (SEM) Evaluation}

One fractured specimen, representative of the predominant fracture mode of each group, was selected for observation under SEM (TESCAN MIRA3; Brno, Czech Republic). Specimens were mounted on aluminum stubs, gold sputter coated (BAL-TEC SDC 050 Sputter Coater, Lichtenstein, Germany), and analyzed at 1.500X. An overview of the structure of each specimen was done at the resin composite/dentin interface, observing the bond integrity, the presence of cracks, and the surface textures of the restorations.

\section{Statistical Analysis}

Statistical analysis was performed with SPSS 16.0 for windows (Chicago, IL, USA). Descriptive statistics (mean and standard deviation) were calculated for $\mu$ TBS. The Shapiro-Wilk test was used to check the normal distribution of the data, and the mean $\mu T B S$ values were subjected to one-way ANOVA after linear transformation of data to obtain normal distribution. The Tukey post hoc test was used for multiple comparisons between groups. For comparison between groups in different storage times ( 24 hours and 6 months), the paired $t$ test was used. The statistical significance was preset at $\alpha=0.05$.

\section{Results}

\section{Microtensile Bond Strength}

The mean $\mu \mathrm{TBS}(\mathrm{MPa}$ ) results are summarized in Table 2. One-way ANOVA revealed statistically significant differences $(p=0.02)$ after the 24 hours storage, with differences between $Z 250$ (51.80 MPa) and $\mathrm{FBF}_{f}(32.03)$. However, after 6 months of storage, no differences were observed ( $p=0.12$ ). No differences were observed between storage times for all groups.

\section{Fracture Mode}

The general fracture mode distribution observed a higher frequency of adhesive failures after 24 hours (54\%) and after 6 months (43\%) for all groups (Table 3). Figures 1 and 2 show the fracture mode distribution per group. At the 24-hour storage time, the highest percentage of adhesive fractures was observed for Filtek Bulk Fill flow (90\%) followed by Tetric Bulk Fill (55\%) and Venus Bulk Fill (55\%) (Fig. 3); and at the 6-month storage time, for Tetric Bulk Fill (55\%) followed by Venus Bulk Fill (50\%) (Fig. 4).
Table 2: Mean $\mu$ TBS (MPa) and standard deviation (SD) for each storage time $(n=20)$

\begin{tabular}{llll}
\hline & \multicolumn{2}{c}{ Mean } & \\
\cline { 2 - 3 } Groups & 24 hours & 6 months & p value \\
\hline Z250 & $51.80(29.13)^{A}$ & $44.71(21.76)$ & 0.65 \\
TBF & $38.58(19.42)^{A B}$ & $32.99(16.30)$ & 0.32 \\
FBF & $40.53(17.04)^{A B}$ & $36.17(24.10)$ & 0.16 \\
VBF & $48.59(17.77)^{A B}$ & $49.10(23.99)$ & 0.71 \\
FBF $_{f}$ & $32.03(16.81)^{\mathrm{B}}$ & $39.80(19.23)$ & 0.23 \\
pvalue $^{2}$ & $0.02 *$ & 0.12 &
\end{tabular}

Different superscript letters indicate statistically significant differences between groups through Tukey post hoc test

${ }^{1}$ One-way ANOVA (column); ${ }^{2}$ paired $t$ test (line); ${ }^{*}$ Statistically significant difference

Table 3: General fracture mode distribution (\%) according to each storage time

\begin{tabular}{|c|c|c|c|c|}
\hline \multirow[b]{2}{*}{ Storage time } & \multicolumn{4}{|c|}{ Fracture mode } \\
\hline & Adhesive (\%) & $\begin{array}{l}\text { Cohesive in } \\
\text { resin (\%) }\end{array}$ & $\begin{array}{l}\text { Cohesive in } \\
\text { dentin (\%) }\end{array}$ & Mixed (\%) \\
\hline 24 hours & 54 & 16 & 14 & 16 \\
\hline 6 months & 43 & 14 & 26 & 17 \\
\hline
\end{tabular}

\section{The SEM Evaluation}

The SEM micrographs of the resin/dentin interface of the fractured specimens are shown in Figures 3 and 4. No remarkable differences were observed between the specimens after 24 hours and 6 months of storage. For all groups, resin monomer penetration into the dentinal tubules and formation of an interdiffusion zone were observed.

The results of this study infer that $\mu$ TBS of class I restorations in permanent molars performed with four bulk-fill composites presented satisfactory values of bonding effectiveness comparable to a conventional resin composite after storage times of 24 hours and 6 months.

\section{Discussion}

The hypothesis that there was no difference in $\mu$ TBS between the bulk-fill resin composites and the conventional incrementally filled resin composite was not rejected.

This result is in accordance with the findings of Öznurhan et al. ${ }^{21}$ The authors attribute the good bond strength results of bulk-fill resin composites to the polymerization modulators, which would enhance the internal stress relieving capacity before reaching the gel point. A polymerization modulator is a photoactive group chemically inserted into urethane methacrylate. The interaction with camphorquinone slowers the development of the modulus of elasticity, leading to reduction in the polymerization stress, without affecting the polymerization rate or degree of conversion. ${ }^{22}$ Ilie et al. ${ }^{23}$ observed similar shear bond strength values of bulk-fill resin composites for both permanent and deciduous teeth, when compared with the conventional resin composite.

On the other hand, Caixeta et al. ${ }^{24}$ found lower pushout bond strength for the bulk-fill resin composite X-tra fil (Voco) when compared to the tested conventional resin composites either in medium or in low viscosity (Filtek Z350 and Filtek Z350 flow-3M/ ESPE, respectively). The material's inorganic composition could 

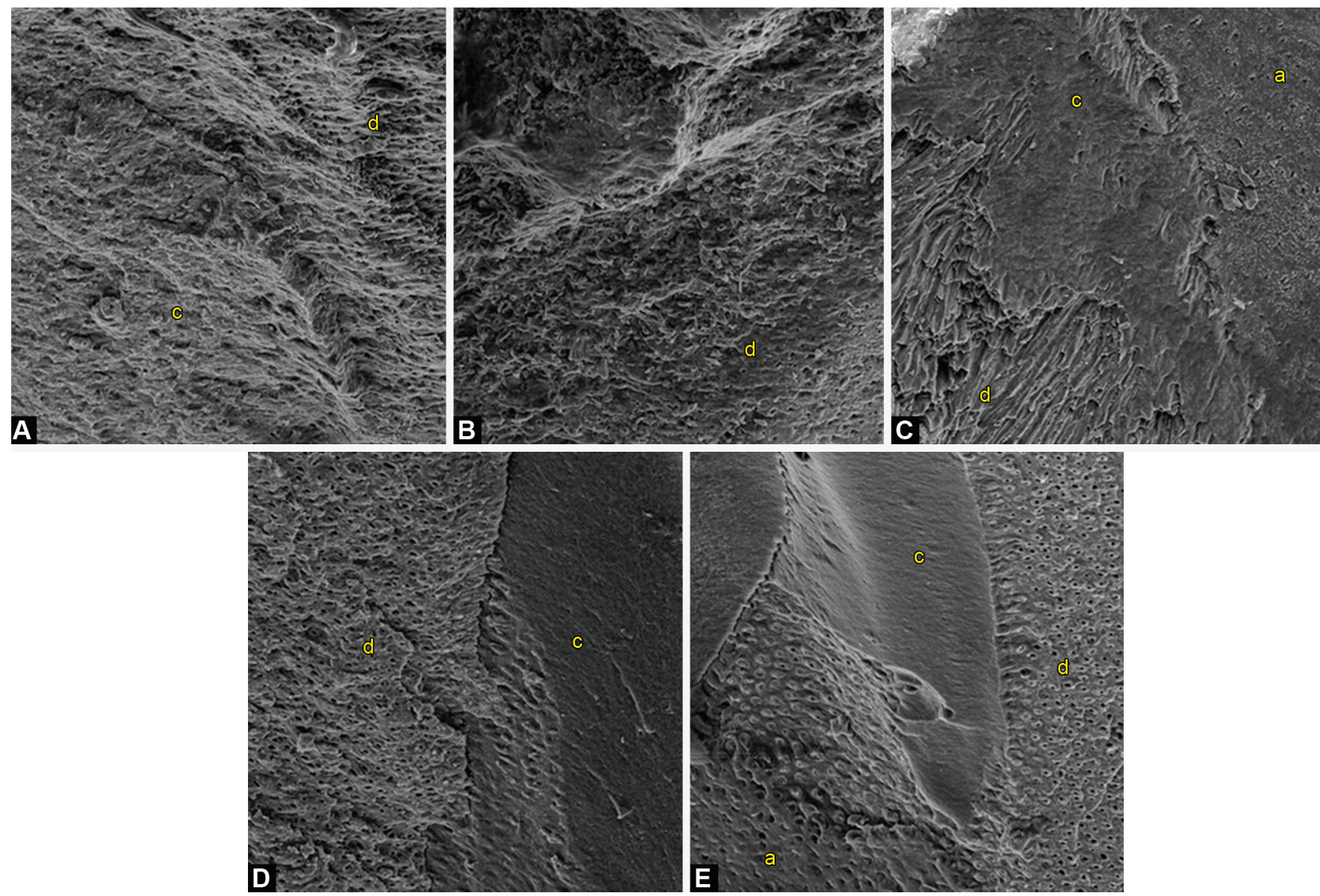

Figs 1 A to E: The SEM photomicrographs (1.500x) of fractured surfaces of specimens stored for 24 hours. (A) Filtek Z250; (B) Tetric EvoCeram Bulk Fill; (C) Filtek Bulk Fill; (D) Venus Bulk Fill; (E) Filtek Bulk Fill Flow. (a) Adhesive layer, (c) Composite resin side, and (d) Dentin side. As failure occurred mainly at the interface, some imprints of the dentin tubule were visible

explain these results: $X$-tra fil has $70.1 \%$ of filler particles, while Filtek Z350 and Filtek Z350 flow have 63.3 and 46\%, respectively. The main factors in reducing the polymerization shrinkage stresses of the bulk-fill resin composites are low flexural modulus and low inorganic content. ${ }^{13}$ Therefore, these results may be attributable to the higher stiffness of the bulk-fill resin composites used. The composition of the organic matrix and filler content volume would approximate the mechanical properties of a microhybrid resin composite, leading to a lower degree of deformation when the load was applied and the consequent disruption of the bond to the cavity walls under lower stress values. According to Leprince et al., ${ }^{14}$ some bulk-fill resin composites have similar characteristics as microhybrid resin composites with high filler particles concentration. In this study, the bulk-fill resin composites and the conventional incrementally filled resin composites showed similar bond strength values.

The restorative filling technique and the type of resin composite can affect the integrity of the bonding layer, particularly in cavities with a high C-factor. Restorations performed with a single increment in restricted cavity yield higher contraction stresses into the pulpal wall that could lead to the disruption of the adhesive layer. Additionally, the materials may not be adequately polymerized in deeper areas. Lower bond strength values were observed after the storage of conventional resin composites in class I restorations when applied in bulk. ${ }^{25}$ However, the higher translucency of the bulk-fill resin composites and the incorporation of polymerization modulators allows them to be used in larger increments ( $4 \mathrm{~mm})$. In this study, no differences were observed between storage times of 24 hours and 6 months, rejecting the second null hypothesis. Analysis of the fracture modes at the 24-hour storage time showed that higher bond strength values were often associated with cohesive failure in the dentin or resin composite (Fig. 3). In general, cohesive failures in dentin or resin and mixed fractures are associated with higher bond strength values. ${ }^{25}$ The adhesive fracture mode was associated with lower bond strength values. ${ }^{23}$

Besides the reduced operative time, bulk-fill resin composites attempt to reduce the polymerization stress at the adhesive interface, especially in high C-factor cavities. Bond strength testing is one of the means to understand the behavior of an adhesive material. Despite the limitations of correlating in vitro results to clinical findings, more extended storage periods are necessary to understand the material's behavior and degradation over time, since time and storage medium influences the final characteristics of the resin composites. ${ }^{26}$ Other factors, such as marginal adaptation and mainly the clinical performance of the materials, are fundamental to predict the longevity of the material. ${ }^{27}$

\section{Conclusion}

Bulk-fill resin composites obtained similar $\mu$ TBS in high C-factor cavities as conventional incrementally filled resin composites. No 

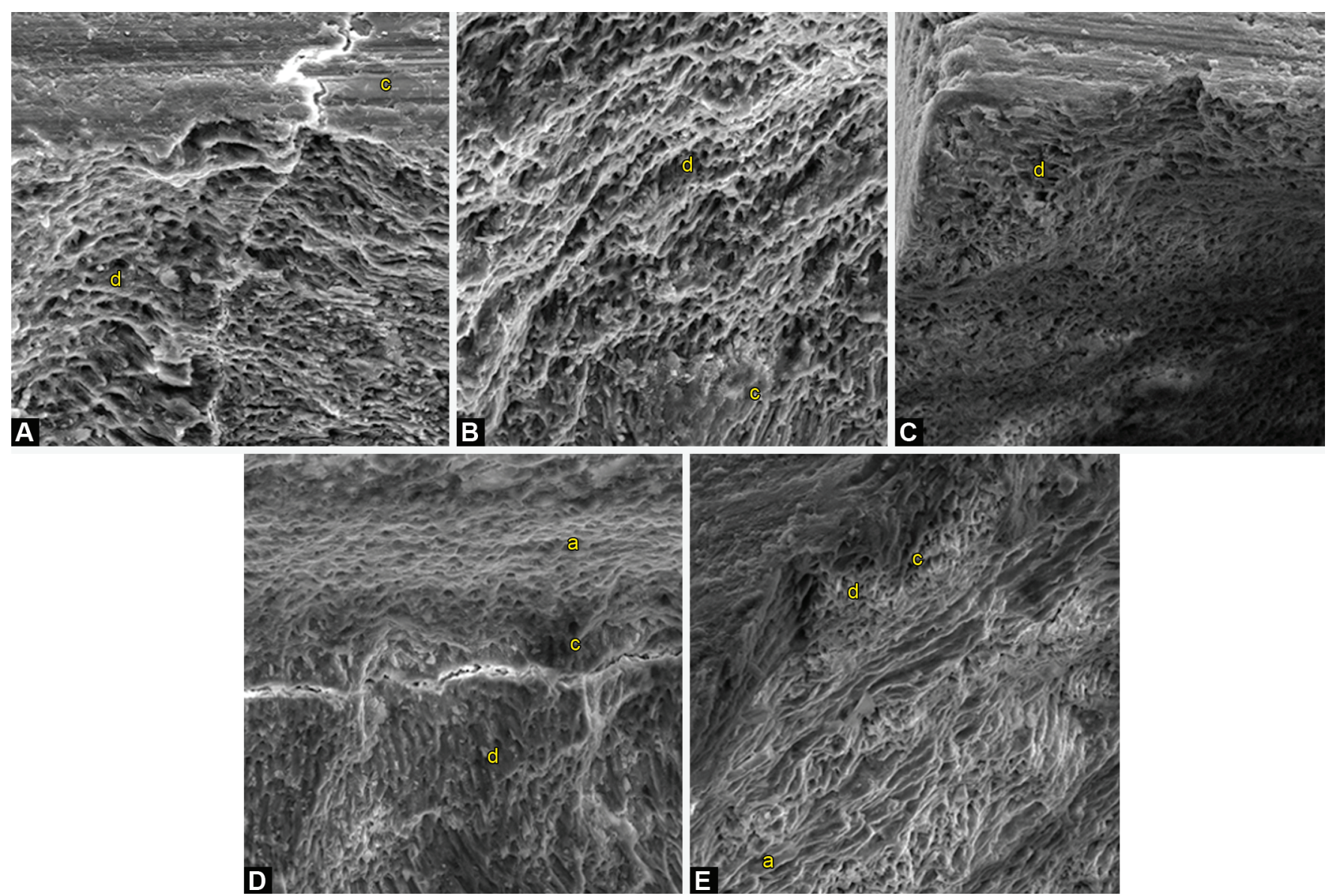

Figs 2A to E: The SEM photomicrographs (1.500X) of fractured surfaces of specimens stored for 6 months. (A) Filtek Z250; (B) Tetric EvoCeram Bulk Fill; (C) Filtek Bulk Fill; (D) Venus Bulk Fill; (E) Filtek Bulk Fill Flow. (a) Adhesive layer, (c) Composite resin side, and (d) Dentin side

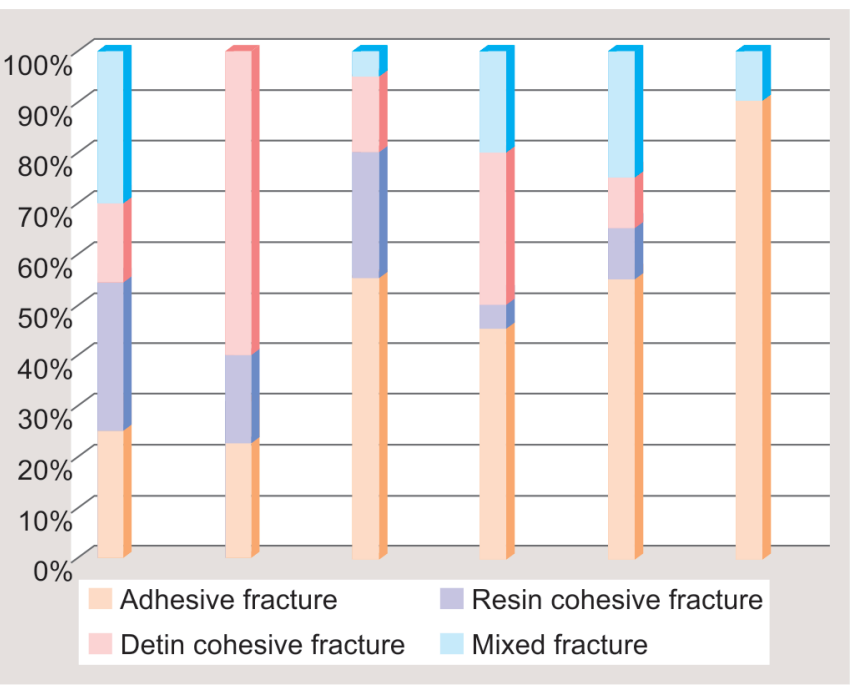

Fig. 3: Fracture mode distribution (\%) per group at 24 hours' storage bond strength reduction was observed after 6 months' storage. Further studies with longer storage times are needed to assess the long-term stability and bulk-fill resin composites.

\section{Clinical Significance}

Single increment restorations in high C-factor cavities with bulk-fill resin composites did not reduce $\mu$ TBS after 24 hours or 6 months storage. The comparable results to the conventional incrementally

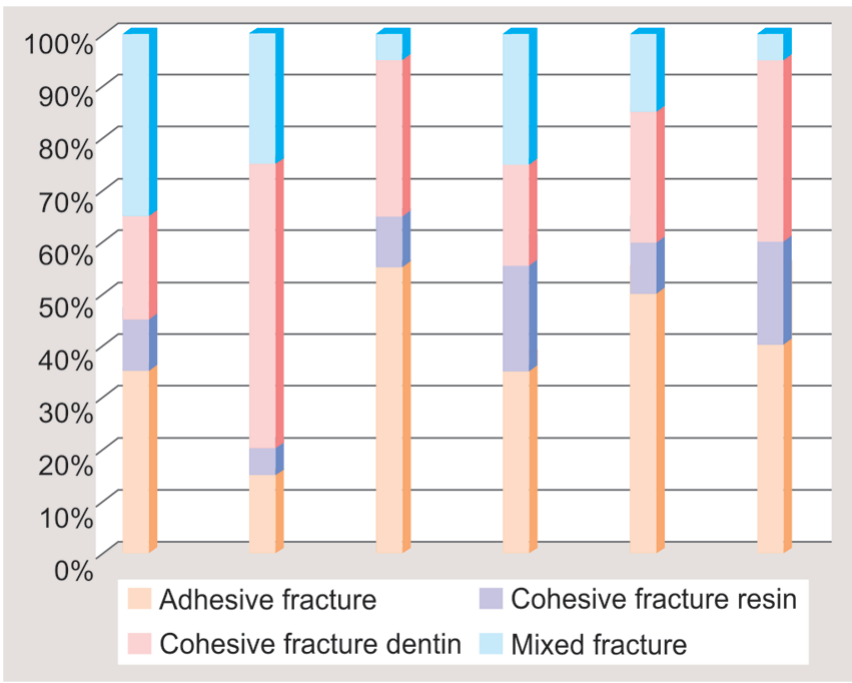

Fig. 4: Fracture mode distribution (\%) per group after 6 months' storage

filled resin composites and the reduction in the operative time make the bulk-fill resin composites a restorative option for posterior teeth restorations.

\section{ACKNOWLEDgments}

The authors are grateful to Sergio dos Santos Silva (Physics Department, Federal University of Pernambuco) for technical assistance with the scanning electron microscope and to the Dental 
School, Universidade de Pernambuco, for all support offered to conduct this research.

\section{References}

1. Chikawa $\mathrm{H}$, Inai $\mathrm{N}$, Cho E, et al. Effect of incremental filling technique on adhesion of light-cured resin composite to cavity floor. Dent Mater J 2006;25(3):503-508. DOI: 10.4012/dmj.25.503.

2. Roggendorf MJ, Krämer N, Appelt A, et al. Marginal quality of flowable 4-mm base vs. Conventionally layered resin composite. J Dent 2011;39(10):643-647. DOI: 10.1016/j.jdent.2011.07.004.

3. Monteiro GQM, Montes MAJR. Evaluation of linear polymerization shrinkage, flexural strength and modulus of elasticity of dental composites. Mater Res 2010;13(1):51-55. DOI: 10.1590/S151614392010000100012.

4. Ilie N, Hickel R. Investigations on a methacrylate-based flowable composite based on the SDR technology. Dent Mater 2011;27(4): 348-355. DOI: 10.1016/j.dental.2010.11.014.

5. El-Safty S, Silikas N, Watts DC. Creep deformation of restorative resin-composites intended for bulk-fill placement. Dent Mater 2012;28(8):928-935. DOI: 10.1016/j.dental.2012.04.038.

6. Sigusch BW, Pflaum T, Völpel A, et al. Resin-composite cytotoxicity varies with shade and irradiance. Dent Mater 2012;28(3):312-319. DOI: 10.1016/j.dental.2011.12.007.

7. Czasch P, llie N. In vitro comparison of mechanical properties and degree of cure of bulk fill composites. Clin Oral Invest 2013;17(1): 227-235. DOI: 10.1007/s00784-012-0702-8.

8. Finan L, Palin WM, Moskwa N, et al. The influence of irradiation potential on the degree of conversion and mechanical properties of two bulk-fill flowable RBC base materials. Dent Mater 2013;29(8):906912. DOI: 10.1016/j.dental.2013.05.008.

9. Garoushi S, Säilynoja E, Vallittu PK, et al. Physical properties and depth of cure of a new short fiber reinforced composite. Dent Mater 2013;29(8):835-841. DOI: 10.1016/j.dental.2013.04.016.

10. Ilie N, Bucuta S, Draenert M. Bulk-fill resin-based composites: An in vitro Assessment of their mechanical performance. Oper Dent 2013;38(6):618-625. DOI: 10.2341/12-395-L.

11. Ilie N, Kessler A, Durner J. Influence of various irradiation processes on the mechanical properties and polymerization kinetics of bulk-fill resin based composites. J Dent 2013;41(8):695-702. DOI: 10.1016/j. jdent.2013.05.008.

12. Didem A, Gözde Y, Nurhan Ö. Comparative mechanical properties of bulk-fill resins. OJCM 2014;4(02):117-121. DOI: 10.4236/ ojcm.2014.42013.

13. El-Damanhoury H, Platt J. Polymerization shrinkage stress kinetics and related properties of bulk-fill resin composites. Oper Dent 2014;39(4):374-382. DOI: 10.2341/13-017-L.
14. Leprince JG, Palin WM, Vanacker J, et al. Physico-mechanical characteristics of commercially available bulk-fill composites. J Dent 2014;42(8):993-1000. DOI: 10.1016/j.jdent.2014.05.009.

15. Benetti A, Havndrup-Pedersen C, Honoré D, et al. Bulk-fill resin composites: Polymerization contraction, depth of cure, and gap formation. Oper Dent 2015;40(2):190-200. DOI: 10.2341/13324-L.

16. Ilie N, Stark K. Effect of different curing protocols on the mechanical properties of low-viscosity bulk-fill composites. Clin Oral Invest 2015;19(2):271-279. DOI: 10.1007/s00784-014-1262-x.

17. Fleming GJ. The potential of a resin-composite to be cured to a 4-mm depth. Dent Mater 2008;24(4):522-529. DOI: 10.1016/ j.dental.2007.05.016.

18. Flury S, Hayoz S, Peutzfeldt A, et al. Depth of cure of resin composites: Is the ISO 4049 method suitable for bulk fill materials? Dent Mater 2012;28(5):521-528. DOI: 10.1016/j.dental.2012.02.002.

19. Furness A, Tadros MY, Looney SW, et al. Effect of bulk/incremental fill on internal gap formation of bulk-fill composites. J Dent 2014;42(4):439-449. DOI: 10.1016/j.jdent.2014.01.005.

20. ISO-Standards., ISO 11405 Dental Materials - Test of Adhesion to Tooth Structure Technical Specification Geneve: International Organization for Standardization 2nd ed., 2003.

21. Öznurhan F, Ünal M, Kapdan A, et al. Flexural and microtensile bond strength of bulk fill materials. JOCPD 2015;39(3):241-246. DOI: 10.17796/1053-4628-39.3.241.

22. Giovannetti A, Goracci C, Vichi A, et al. Post retentive ability of a new resin composite with low stress behavior. J Dent 2012;40(4):322-328. DOI: 10.1016/j.jdent.2012.01.007.

23. Ilie N, Schöner C, Bücher K, et al. An in-vitro assessment of the shear bond strength of bulk-fill resin composites to permanent and deciduous teeth. J Dent 2014;42(7):850-855. DOI: 10.1016/ j.jdent.2014.03.013.

24. Caixeta RV, Guiraldo RD, Kaneshima EN, et al. Push-out bond strength of restorations with bulk-fill, flow, and conventional resin composites. Sci World J 2015. 11-13. DOI: 10.1155/2015/452976.

25. Van Ende A, De Munck J, Van Landuyt KL, et al. Bulk-filling of high C-factor posterior cavities: Effect on adhesion to cavitybottom dentin. Dent Mater 2013;29(3):269-277. DOI: 10.1016/ j.dental.2012.11.002.

26. De Brito OFF, De Oliveira ILM, Monteiro GQM. Hydrolytic and biological degradation of bulk-fill and self-adhering resin composites. Oper Dent 2019;44(5):223-233. DOI: 10.2341/17-390-L.

27. Veloso SRM, Lemos CAA, de Moraes SLD, et al. Clinical performance of bulk-fill and conventional resin composite restorations in posterior teeth: a systematic review and meta-analysis. Clin Oral Investig 2019;23(1):221-233. DOI: 10.1007/s00784-0182429-7. 